\title{
Surgical site infection prevalence and associated factors in Hawassa University comprehensive specialized hospital, southern Ethiopia.
}

Bedilu Deribe ( $\sim$ bediludribe2002@gmail.com )

Hawassa University College of Medicine and Health Sciences

Wegene Jemebere

Hawassa University College of Medicine and Health Sciences

Gezahegn Bekele

Hawassa University College of Medicine and Health Sciences

Research article

Keywords: Prevalence, surgical site infection, associated factors, Ethiopia

Posted Date: October 4th, 2019

DOI: https://doi.org/10.21203/rs.2.15549/v1

License: (우 This work is licensed under a Creative Commons Attribution 4.0 International License.

Read Full License 


\section{Abstract}

Background Surgical site infections (SSIs) continue the main problem in health care facilities, causing the prolonged length of stay, considerable morbidity, mortality, and the extra cost to patients after surgery. The aim of this study was to determine the prevalence of SSIs and explore its associated factors among surgical patients at Hawassa university comprehensive specialized hospital, southern Ethiopia.

Methods A hospital-based cross-sectional study design was conducted among post-operative patients on a sample of 281 who were admitted and have had surgery from 1 March - 1 April 2019. Purposive sampling technique and the structured questioner were selected to gather data from the patient's medical record, interview, and observation. EPI Info 3.5.4 was a data entry software and SPSS version 20.0 was selected for analysis. Associations among variables were assessed by binary logistic regression.

Result A total of 281 patients have participated and the mean age was $30.3( \pm 18.9)$ years. The prevalence

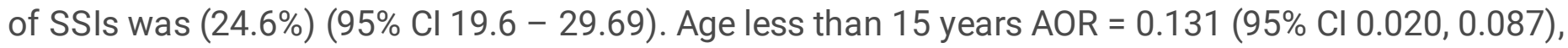
having clean surgical wound $A O R=0.006(95 \% \mathrm{Cl} 0.002,0.024)$ were significant protective associated factors to SSIs while having open surgical wound AOR $=5.189(95 \% \mathrm{Cl} 1.511,17.821)$ and malnutrition AOR $=29.351(95 \% \mathrm{Cl} 5.711,150.851)$ were significant risk associated factors to SSIs.

Conclusion The prevalence of SSIs was bigger than the worldwide range between (1.2\%) and (5.2\%) even higher compared to reports from several developing countries. This needs exceptional attention to reduce the odds of surgical site infection by standardizing patient care and controlling of comorbidities.

\section{Background}

Surgical site infections circle as many as 30 days after surgery (or as late as one year after surgery in patients with implants) $(1,2)$.

Among hospital-acquired infections, surgical site infections (SSI) are the most frequently reported. The incidence of SSI could be nearly 4 times higher in low and middle-income countries (LMIC) than in high-income countries (3).

Surgical site infections were the primary infections in hospitals of Africa higher than magnitudes noted in developed countries (3) with cumulative incidence extended from $2.5 \%$ to $30.9 \%(4)$. In Ethiopia, the incidence rate of SSIs ranges from $10.9 \%$ to $75 \%(5-8)$.

Although SSIs are preventable complications following surgery, they are associated with longer hospitalization; pain; discomfort; delayed wound healing; prolonged or permanent disability; and, in worst cases, death (9). Additionally, SSI places a significant economic burden on health system and patient finances and resources because of lengthier hospitalizations and increased cost of treatment (10). 
SSI comprise a multifaceted relationship among numerous factors: patient, microbial, surgical, and environmental (11). Patient-related factors includes, age (5, 12-14), poor nutritional state (12) obesity (15), (16) and presence of pre-morbid illness $(5,12,16,17)$. Prolonged duration of the operation (18), (5), (12), (17), significant contamination of the incision (12), (14), long postoperative hospital stay (18), (5), (14), inadequate prophylactic antibiotic therapy (18), (12), (16), type of anesthesia (19), also associated with SSIs.

Surgical procedures are associated with high infection rates and mortality in developing countries because necessary resources are inadequate (20), (13).

According to the World health organization (WHO) and other studies, episodic investigation on SSIs prevalence and its related issues can reduce SSIs by up to 50\% (21), (22).

There are inadequate studies concerning the prevalence of SSIs and its linked factors in Ethiopia particularly in Hawassa. Hence, this study required to determine the prevalence of SSI and explore its associated factors at Hawassa University comprehensive specialized hospital in southern Ethiopia.

The result of this study will provide baseline information to develop evidence-based strategies to diminish preventable SSIs and their adverse effects by the Federal Ministry of the health of Ethiopia and concerned non-governmental organizations.

\section{Methods}

\section{Study design and setting}

A hospital-based cross-sectional study was done from 1 March - 1 April 2019. Hawassa is situated at the eastern shore of Lake Hawassa and is located $275 \mathrm{~km}$ to the south of Addis Ababa, the capital city of the country. Hawassa University comprehensive specialized hospital is located in the south part of Hawassa town in the SNNPR regional state. The University Hospital is the only biggest comprehensive specialized referral and teaching hospital in the region. It is giving inpatient and as an outpatient service for more than 25 million people from the surrounding zones and nearby regions. This teaching hospital consists of an operating room, intensive care unit (ICU), 16 wards with 400 beds, and 11 outpatient departments. The study was carried out at surgical ward.

\section{Sample size and sampling procedure}

The sample size was determined by using a single population proportion formula with a $95 \%$ confidence interval, a 5\% margin of error and adding 5\% contingency for illegible handwriting and incomplete medical records. 
By using the proportion of prevalence of Surgical site infection $35 \%$ as published data was acquired from the Addis Ababa study (23) the sample size was calculated as follows.

$$
=350
$$

Therefore, by adding $10 \%$ for possible non-response rate, the final sample size was $=\mathbf{3 8 5}$.

Then since the study population is $<10,000$ correction formula was used as follows:

$$
1+n i \quad n+N
$$

Sample size $=n i=\mathrm{Ni} \times \mathrm{N}=385 * 1049 / 385+1049(\mathrm{~N}=$ total surgical patients admitted to surgical ward to 1 March to 1 April 2019) = 281 total sample size

The sampling technique was purposive because the patients visiting the health care for disease conditions are random by their nature until the required sample sizes are filled.

\section{Data collection tools and procedures}

A structured data collection tool was used to capture data from medical records, patient charts and study participants who developed surgical site infections.

The selected patients were assessed by physical examination using the observational checklist adopted from the US Center for Disease Control and Prevention (CDC) criteria (24).

SSIs was diagnosed in the presence of as a minimum one of the next signs or symptoms of infection after surgery within 30 days : (a) pain, tenderness, localized swelling, redness, heat or purulent discharge with or without laboratory confirmation in cases of superficial incisional infections; (b) evidence of abscess or fever of $>38^{\circ} \mathrm{C}$ in infections of the deep incision; (c) localized pain or tenderness with an organism isolated from an organ/space infection; and (d) positive culture from wound drainage or percutaneous aspiration.

Data on site-specific SSI, patient data including demographics, clinical and surgical procedures, and possible risk factors were collected by 4 trained BSc nurses with data collection experience.

The data collectors were trained for one day on data collection methodology and related issues prior to the start of data collection and were closely supervised by 2 MSc nurses during the data collection. Filled checklists were checked on a daily bases for completeness, clarity, and accuracy. Data cleaning was undertaken before entry and analysis.

\section{Statistical analysis}

Data entry was done by using EPI Info 3.5.1 and exported to SPSS version 20.0 software package for analysis. The descriptive analysis including frequency and cross tabs were used to assess the frequency of variables with independent variables. Binary logistic regression 
was carried out to assess the association of dependent variable with independent variables and to determine predictors of SSI using odds ratios with 95\% confidence interval (CIs). Finally, forward stepwise logistic regression model with all independent variables having pvalue $<0.25$ were fitted and adjusted odds ratio (AORs) were calculated to identify independent predictors of SSI among patients undergone surgery. A value of $p<0.05$ was considered statistically significant.

\section{Results}

\section{Socio-demographic characteristics of the study participants}

A total of 281 patients have participated and the age ranged from 1 to 80 years with the mean age of $30.3( \pm 18.9)$ years. Female accounts $(54.1 \%)$ and more than half of them were from rural in residency (51.6\%). Concerning the educational status of the participants, the majority (38.1\%) accomplished grades 1-8. (Table1).

Table 1: Socio-demographic characteristics of surgical patients at Surgical ward of Hawassa University comprehensive specialized hospital, Hawassa, SNNPR, Ethiopia, from 1 March - 1 April 2019 ( $n=281)$.

\begin{tabular}{ccll}
\hline Socio-demographic characteristics & Frequency & Percent \\
\hline Age & $<15$ year & 69 & 24.6 \\
& $15-65$ year & 195 & 69.4 \\
\hline Sex & $>65$ year & 17 & 6.0 \\
\hline \multirow{2}{*}{ Residency } & Male & 129 & 45.9 \\
\hline \multirow{2}{*}{ Educational status } & Female & 152 & 54.1 \\
\hline & Urban & 136 & 48.4 \\
\hline & Rural & 145 & 51.6 \\
& Reable to read and write & 84 & 29.9 \\
& Read and write only & 25 & 8.9 \\
\hline & Grade 1-8 & 107 & 38.1 \\
\hline & Grade 9-12 & 26 & 9.3 \\
\hline & Certificate and above & 39 & 13.9 \\
\hline
\end{tabular}

\section{The Surgical condition and clinical characteristics of patients}


Local anesthesia was given for (59.8\%) of patients and the majority (82.9\%) stayed one hour or less in a surgical procedure. Antibiotic prophylaxis was given to (51.6\%) patients before surgery and (61.9\%) were operated in emergency surgery. Preoperative surgical site shaving was given to (29.2\%) of patients and abdominal surgery was the largest (57.3\%). The majority of patients $(69.9 \%)$ had a clean wound and $(86.8 \%)$ of the surgical site was closed. Sign and symptoms of malnutrition were identified on (10.0\%) of patients while nine of the respondent were identified with comorbid diseases which indicates immunosuppression like Tuberculosis, HIV/AIDS and diabetes. (Table 2).

Table 2: Surgical condition and clinical characteristics of patients at Surgical ward of Hawassa University comprehensive specialized hospital, Hawassa, SNNPR, Ethiopia, from 1 March - 1 April 2019 (n=281). 


\begin{tabular}{|c|c|c|c|}
\hline \multicolumn{2}{|c|}{ Surgical condition and clinical characteristics } & \multirow{2}{*}{$\begin{array}{l}\text { Frequency } \\
168\end{array}$} & \multirow{2}{*}{$\frac{\text { Percent }}{59.8}$} \\
\hline Type of anesthesia & Local & & \\
\hline & General & 113 & 40.2 \\
\hline \multirow[t]{2}{*}{ Duration of surgery in hour } & $\leq 1$ hour & 233 & 82.9 \\
\hline & $\geq 2$ hours & 48 & 17.1 \\
\hline \multicolumn{2}{|c|}{ Antibiotic prophylaxis before surgery Yes } & 160 & 51.6 \\
\hline & No & 121 & 48.4 \\
\hline \multirow[t]{2}{*}{ Type of surgery } & Elective & 107 & 38.1 \\
\hline & Emergency & 174 & 61.9 \\
\hline \multirow[t]{2}{*}{ Preoperative surgical site shaving } & Yes & 82 & 29.2 \\
\hline & No & 199 & 70.8 \\
\hline \multirow[t]{5}{*}{ Site of surgery } & Head & 13 & 4.6 \\
\hline & Upper extremities & 28 & 10.0 \\
\hline & Lower extremities & 68 & 24.2 \\
\hline & Abdomen & 161 & 57.3 \\
\hline & Genital areas & 11 & 3.9 \\
\hline \multirow[t]{4}{*}{ Types of wound } & Clean & 196 & 69.9 \\
\hline & Clean contaminated & 52 & 18.5 \\
\hline & Contaminated & 30 & 10.7 \\
\hline & Dirty & 3 & 1.1 \\
\hline \multirow[t]{2}{*}{ The condition of the surgical site } & Opened & 37 & 13.2 \\
\hline & Closed & 244 & 86.8 \\
\hline \multirow[t]{2}{*}{ Sign and symptom of Malnutrition } & Yes & 28 & 10.0 \\
\hline & No & 253 & 90.0 \\
\hline \multicolumn{4}{|l|}{ Comorbid diseases indicating } \\
\hline \multirow[t]{3}{*}{ Immunosuppression } & Tuberculosis & 6 & 2.1 \\
\hline & HIV/ AIDS & 2 & 0.7 \\
\hline & Diabetic mellitus & 1 & 0.4 \\
\hline
\end{tabular}

\section{Prevalence of Surgical Site Infection}

A total of 69 out of 281 patients developed surgical site infections giving an overall prevalence (24.6\%) with (95\% CI [19.6 - 29.69). (Figure 1).

Figure 1: Prevalence of surgical site infection at Surgical ward of Hawassa University comprehensive specialized hospital, Hawassa, SNNPR, Ethiopia, from 1 March - 1 April $2019(n=281)$. 


\section{Factors associated with surgical site infection}

Different studies indicate the age of patients has effect on the development of surgical site infection. This study identified that SSIs was higher in older patients whose ages $>65$ years $(41.2 \%)$ and patients $<15$ years were $(86.9 \%)$ less likely to develop surgical site infection as compared to those above 65 years old $(\mathrm{AOR}=0.131,95 \%$ CI $0.020,0.087)$.

Those patients who received local anesthesia developed SSI almost twice (30.4\%) than general anesthesia receivers (15.9\%) and they were 2.3 times more likely to develop surgical site infection if all other factors were kept constant (COR=2.301, 95\% CI 1.260, 4.199) but not statistically significant in multivariate analysis.

According to this study, the prevalence of SSIs among clean and clean-contaminated wounds was (5.1\%) and (69.4\%) respectively. Patients with clean wounds were (99.4\%) less likely to develop surgical site infection as compared to those patients with the cleancontaminated wounds (AOR=0.006, 95\% CI 0.002, 0.024).

This study also identified in open kept surgical sites, the odds of developing surgical site infection was 5.2 times as compared to close kept surgical site (AOR= 5.189, 95\% CI 1.511, 17.821).

The prevalence of SSI in those patients with Malnutrition was more than three folds (64.3\%) and malnourished patients were 29.3 times more likely to develop SSIs than well-nourished patients $(A O R=29.351$ 95\% CI 5.711, 150.851). Details of factors associated with surgical site infection were presented in (Table 3). 
Table 3: Factors associated with SSIs at Surgical ward of Hawassa University comprehensive specialized hospital, Hawassa, SNNPR, Ethiopia, from 1 March - 1 April $2019(\mathrm{n}=281)$ 


\begin{tabular}{|c|c|c|c|c|c|}
\hline \multirow[t]{2}{*}{ iables } & & \multicolumn{2}{|c|}{$\begin{array}{l}\text { Surgical site } \\
\text { infection }\end{array}$} & \multirow[t]{2}{*}{$\begin{array}{l}\text { COR }(95 \% \\
\text { CI) }\end{array}$} & \multirow[t]{2}{*}{$\begin{array}{l}\text { AOR }(95 \% \\
\text { CI) }\end{array}$} \\
\hline & & NO SSI & SSI & & \\
\hline \multirow[t]{5}{*}{ group in Years } & $<15$ & $\begin{array}{l}57 \\
(82.6 \%)\end{array}$ & $\begin{array}{l}12 \\
(17.4 \%)\end{array}$ & $\begin{array}{l}0.301(0.095 \\
0.949) *\end{array}$ & $\begin{array}{l}0.131(0.020, \\
0.087) *\end{array}$ \\
\hline & $15-65$ & $\begin{array}{l}145 \\
(74.4 \%)\end{array}$ & $\begin{array}{l}50 \\
(25.6 \%)\end{array}$ & $\begin{array}{l}0.493(0.178, \\
1.363)\end{array}$ & $\begin{array}{l}0.363(0.042, \\
3.112)\end{array}$ \\
\hline & $>65$ & $\begin{array}{l}10 \\
(58.8 \%)\end{array}$ & $\begin{array}{l}7 \\
(41.2 \%)\end{array}$ & 1 & 1 \\
\hline & Male & $\begin{array}{l}91 \\
(70.5 \%)\end{array}$ & $\begin{array}{l}38 \\
(29.5 \%)\end{array}$ & 1 & 1 \\
\hline & Female & $\begin{array}{l}121 \\
(79.6 \%)\end{array}$ & $\begin{array}{l}31 \\
(20.4 \%)\end{array}$ & $\begin{array}{l}1.630(0.943, \\
2.816)\end{array}$ & $\begin{array}{l}1.540(0.627, \\
3.782)\end{array}$ \\
\hline \multirow[t]{2}{*}{ idence } & Rural & $\begin{array}{l}109 \\
(81.1 \%)\end{array}$ & $\begin{array}{l}27 \\
(19.9 \%)\end{array}$ & 1 & 1 \\
\hline & Urban & $\begin{array}{l}103 \\
(71.0 \%)\end{array}$ & $\begin{array}{l}42 \\
(29.0 \%)\end{array}$ & $\begin{array}{l}0.607(0.349, \\
1.057)\end{array}$ & $\begin{array}{l}1.534(0.630, \\
3.737)\end{array}$ \\
\hline \multirow[t]{2}{*}{ e of anesthesia } & Local & $\begin{array}{l}117 \\
(69.6 \%)\end{array}$ & $\begin{array}{l}51 \\
(30.4 \%)\end{array}$ & $\begin{array}{l}2.301(1.260 \\
4.199) *\end{array}$ & $\begin{array}{l}1.733(0.616, \\
4.878)\end{array}$ \\
\hline & General & $\begin{array}{l}95 \\
(84.1 \%)\end{array}$ & $\begin{array}{l}18 \\
(15.9 \%)\end{array}$ & 1 & 1 \\
\hline \multirow[t]{2}{*}{$\begin{array}{l}\text { ation of surgery in } \\
\text { Ir }\end{array}$} & $\leq 1$ hour & $\begin{array}{l}176 \\
(75.5 \%)\end{array}$ & $\begin{array}{l}57 \\
(24.5 \%)\end{array}$ & 1 & 1 \\
\hline & $\geq 2$ hours & $\begin{array}{l}36 \\
(75.0 \%)\end{array}$ & $\begin{array}{l}12 \\
(25.0 \%)\end{array}$ & $\begin{array}{l}0.972(0.474, \\
1.993)\end{array}$ & $\begin{array}{l}1.272(0.445, \\
3.639)\end{array}$ \\
\hline \multirow[t]{2}{*}{$\begin{array}{l}\text { biotic prophylaxis } \\
\text { re surgery }\end{array}$} & Yes & $\begin{array}{l}110 \\
(71.4 \%)\end{array}$ & $\begin{array}{l}44 \\
(28.6 \%)\end{array}$ & $\begin{array}{l}1.632(0.932, \\
2.857)\end{array}$ & $\begin{array}{l}1.631(0.618, \\
4.303)\end{array}$ \\
\hline & No & $\begin{array}{l}102 \\
(80.3 \%)\end{array}$ & $\begin{array}{l}25 \\
(19.7 \%)\end{array}$ & 1 & 1 \\
\hline \multirow[t]{2}{*}{ ies of Surgery } & Elective & $\begin{array}{l}81 \\
(75.7 \%)\end{array}$ & $\begin{array}{l}26 \\
(24.3 \%)\end{array}$ & $\begin{array}{l}0.978 \\
(0.558,1.712)\end{array}$ & $\begin{array}{l}1.617 \\
(0.473,5.523)\end{array}$ \\
\hline & Emergency & $\begin{array}{l}131 \\
(75.3 \%)\end{array}$ & $\begin{array}{l}43 \\
(24.7 \%)\end{array}$ & 1 & 1 \\
\hline \multirow[t]{2}{*}{$\begin{array}{l}\text { operative surgical } \\
\text { shaving }\end{array}$} & Yes & $\begin{array}{l}60 \\
(73.2 \%)\end{array}$ & $\begin{array}{l}22 \\
(26.8 \%)\end{array}$ & 1 & 1 \\
\hline & No & $\begin{array}{l}152 \\
(76.4 \%)\end{array}$ & $\begin{array}{l}47 \\
(23.6 \%)\end{array}$ & $\begin{array}{l}1.186(0.659, \\
2.135)\end{array}$ & $\begin{array}{l}2.626(0.722, \\
9.552)\end{array}$ \\
\hline \multirow[t]{2}{*}{$\begin{array}{l}\text { ie of surgical } \\
\text { and }\end{array}$} & Clean & $\begin{array}{l}186 \\
(94.9 \%)\end{array}$ & $\begin{array}{l}10 \\
(5.1 \%)\end{array}$ & $\begin{array}{l}0.24(0.011 \\
0.052)^{*}\end{array}$ & $\begin{array}{l}0.006(0.002, \\
0.024)^{*}\end{array}$ \\
\hline & $\begin{array}{l}\text { Clean } \\
\text { contaminated }\end{array}$ & $\begin{array}{l}26 \\
(30.6 \%)\end{array}$ & $\begin{array}{l}59 \\
(69.4 \%)\end{array}$ & 1 & 1 \\
\hline \multirow[t]{2}{*}{$\begin{array}{l}\text { condition of } \\
\text { gical site }\end{array}$} & Open & $\begin{array}{l}20 \\
(51.4 \%)\end{array}$ & $\begin{array}{l}17 \\
(45.9 \%)\end{array}$ & $\begin{array}{l}3.138(1.535 \\
6.419)^{*}\end{array}$ & $\begin{array}{l}5.189(1.511, \\
17.821)^{*}\end{array}$ \\
\hline & Closed & $\begin{array}{l}192 \\
(78.7 \%)\end{array}$ & $\begin{array}{l}52 \\
(21.3 \%)\end{array}$ & 1 & 1 \\
\hline $\begin{array}{l}\mathrm{n} \text { and symptom of } \\
\text { Inutrition }\end{array}$ & Yes & $\begin{array}{l}10 \\
(35.7 \%)\end{array}$ & $\begin{array}{l}18 \\
(64.3 \%)\end{array}$ & $\begin{array}{l}7.129(3.103, \\
16.380)^{*}\end{array}$ & $\begin{array}{l}29.351 \\
(5.711, \\
150.851)^{*}\end{array}$ \\
\hline
\end{tabular}




\begin{tabular}{|c|c|c|c|c|c|}
\hline & No & $\begin{array}{l}202 \\
(79.8 \%)\end{array}$ & $\begin{array}{l}51 \\
(20.2 \%)\end{array}$ & 1 & 1 \\
\hline $\begin{array}{l}\text { Lorbid diseases } \\
\text { zating }\end{array}$ & Yes & $4(44.4 \%)$ & 5 (55.6\%) & $\begin{array}{l}4.062(1.059, \\
15.582)^{*}\end{array}$ & $\begin{array}{l}0.159(0.015, \\
1.705)\end{array}$ \\
\hline lunosuppression & No & $\begin{array}{l}208 \\
(76.5 \%)\end{array}$ & $\begin{array}{l}64 \\
(23.5 \%)\end{array}$ & 1 & 1 \\
\hline
\end{tabular}

\section{Discussion}

Surgical site infections persist the worrying threat to the patient undergoing surgery Decreasing the prevalence of modifiable risk factors by up-to-date strategies and interventior prior to surgery may decrease the threat of infection.

The prevalence of SSIs was (24.6 \%) (95\% CI 19.6 - 29.69). The finding is higher to those o studies conducted in Mekelle Ethiopia (11.1\%) (8), Jimma Ethiopia (11.4\%) (25), Hawassc Ethiopia (19.1\%) (26), Uganda (16.4\%) (27), Pakistan (8.6\%) (28), Vietnam ( 10.9\%) (29) India (5\%) (30) and Bolivia (12\%) (31). This higher SSIs prevalence could be due to variou: issues like high flow patients as the hospital served more than 25 million people which caust overcrowding, lack of adequate postoperative care, shortage of trained manpower, failure tc preserve sterility during surgical procedures, insufficient infection control due to deprivec hygiene and water shortage, resource and structural constraints, and lack of awarenes: regarding SSIs among the overall population.

This study identified that SSIs were higher in older patients aged above 65 years and patient: less than 15 years were (86.9\%) less likely to develop surgical site infection as compared tc those above 65 years (AOR $=0.131,95 \%$ CI 0.020, 0.087). The result was similar to othe] studies (26), (28) approving that when age advances the risk of SSIs increases.

According to this study, the prevalence of SSIs among clean and clean-contaminated wounds was (5.1\%) and (69.4\%) respectively. Patients with clean wounds were (99.4\%) less likely to develop surgical site infection as compared to those patients with cleancontaminated wounds ( $\mathrm{AOR}=0.006,95 \% \mathrm{CI} 0.002,0.024$ ). The finding was coherent with other researches done in Addis Ababa Ethiopia as the SSIs prevalence was higher in cleancontaminated wounds (50.0\%) than clean wound (15.7\%) (23), in Mekelle Ethiopia (29.5\%) against (8.3\%) (8), in Sudan (9.5\%) versus (8\%) (32) also in Bolivia (13.9\%) compared to , (6.9\%) (31). The low prevalence of SSIs on clean wounds in this study could be due to more precaution including antibiotic use for most clean wounds in the study setting. 
This study also identified, in open kept surgical sites, the odds of developing surgical site infection was 5.2 times as compared to close kept surgical site (AOR=5.189, 95\% CI 1.511, 17.821). The result was consistent with Indian study as the open wound is exposed to potential contamination from time of incision and closure (30).

The prevalence of SSI in those patients with Malnutrition was more than three folds anc malnourished patients were 29.3 times more likely to develop SSIs than well-nourishec patients $(\mathrm{AOR}=29.351$ 95\% CI 5.711, 150.851). The finding is similar to other studies a: Malnutrition is a well-documented risk factor for SSI (27), (28), (33).

\section{Limitation of the study}

Since the study design was cross-sectional, it is difficult to establish a sequential relationshir between surgical site infections and descriptive variables. Further, a short study perioc limited us to take large sample size. Also due to resource shortage, variables related tc health professional's infection prevention practice, equipment sterilization methods and type: of antiseptics used for patient preparation were not studied.

\section{Conclusions}

The prevalence of SSIs was bigger than the worldwide range (1.2\%) to $(5.2 \%)$, even highe] compared to reports from many developing countries and it is a significant problem in the study hospital. Age greater than 65 years old, presence of clean-contaminated wounds keeping surgical sites open and Malnutrition were independently associated factors for SSIs Moreover, Antibiotic prophylaxis and surgical site shaving before surgery were not identifiec as a protective associated factor for SSIs. Presence of Immunosuppression indicatins comorbid diseases like Tuberculosis, HIV/AIDS and Diabetes and taking local anesthesic were identified as predictors of SSIs but the association was not solid enough.

Therefore, to challenge the burden of SSI in the hospitals, special consideration is needed tc reduce the odds of surgical site infection by standardizing patient care, implementing WHC surgical safety protocol and controlling of comorbidities. Also, extraordinary devotion shoulc be given to infection prevention strategies, establishing strict sterile environment and aseptic surgical techniques.

Furthermore, a periodic study on prevalence and associated factors with long study perioc and large sample size may further decrease the burden of SSIs.

\section{Declarations}

\section{List of abbreviations}

SSIs: surgical site infections; BSc: Bachelor of Science; MSc: Masters of Science; CDC Center for Disease Control and Prevention; WHO: World Health Organization; LMIC: Low- tc Middle-Income Countries; IRB: Institutional review board of Hawassa University; SNNPRS 
Southern Nations Nationalities and Peoples Region; COR: crude odds ratio; AOR: adjustec odds ratio; CI: confidence interval; SPSS: Statistical Package for Social Sciences.

\section{Ethical consideration}

A written ethical clearance was obtained from the Institutional Review Board of Hawassa University, Hawassa, Ethiopia. A formal letter of cooperation was written to the Hawassa University comprehensive specialized hospital and permission were obtained prior to the beginning of data collection. After the provision of sufficient information about the purpose of the study, verbal and written consent was obtained from all study participants.

\section{Consent for publication}

Not applicable.

\section{Availability of data and materials}

All data generated or analyzed during this study are included in this published. We sent al data which are available; there is no remaining data and materials.

\section{Competent interests}

The authors declare no conflict of interest

\section{Funding and sponsorship}

This research was funded by Hawassa University for the academic staff's fund. The role o the funding body was to expense the cost for data collection, analysis, and interpretation There is no any fund for publication. The study design and manuscript was designed anc written by authors.

\section{Acknowledgment}

We are very grateful to the college of medicine and health sciences of Hawassa Universit for technical and financial support. The authors also acknowledge data collectors whe showed the greatest effort in acquiring appropriate information. The hospital also deserve: thanks for the assistance and permission to undertake the research. 


\section{Authors' contribution}

BD, WJ, and GB conceived of and designed the study, participated in data collection analyzed the data and drafted the paper. BD and WJ critically reviewed the study protocol participated in data acquisition and analysis and reviewed the draft manuscript. All author: read and approved the final manuscript.

Authors' information

Bedilu Deribe (BD) ${ }^{1 \alpha}$ : MSc in adult health nursing, school of nursing, college of medicin and health sciences, Hawassa University, Hawassa, Ethiopia.

Wegene Jemebere (WJ) ${ }^{1}$ : MSc in adult health nursing, school of nursing, college of medicin and health sciences, Hawassa University, Hawassa, Ethiopia.

Gezahegn Bekele (GB) ${ }^{1}$ : MSc in adult health nursing, school of nursing, college of medicine and health sciences, Hawassa University, Hawassa, Ethiopia.

\section{References}

1. Owens C, Stoessel KJJoHI. Surgical site infections: epidemiology, microbiology and prevention. 2008;70:3-10.

2. Anderson DJ, Kaye KSJIDCoNA. Staphylococcal surgical site infections. 2009;23(1):53-72.

3. Allegranzi B, Bagheri Nejad S, Chraiti M, Castillejos G, Kilpatrick C, Kelley EJG, Switzerland: World Health Organization. Report on the burden of endemic health care-associated infection worldwide. 2011.

4. Nejad SB, Allegranzi B, Syed SB, Ellis B, Pittet DJBotWHO. Health-care-associated infection in Africa: a systematic review. 2011;89:757-65.

5. Mulu W, Kibru G, Beyene G, Damtie H. Associated risk factors for postoperative nosocomial infections among patients admitted at Felege Hiwot Referral Hospital, Bahir Dar, Northwest Ethiopia. Clin Med Res. 2013;2(6):140-7.

6. Mengesha RE, Kasa BG-S, Saravanan M, Berhe DF, Wasihun AGJBrn. Aerobic bacteria in post surgical wound infections and pattern of their antimicrobial susceptibility in Ayder Teaching and Referral Hospital, Mekelle, Ethiopia. 2014;7(1):575. 
7. Gedefaw G, Asires A, Shiferaw S, Addisu D. Factors associated with surgical site infection among women undergoing obstetrics surgery at Felegehiwot Referral Hospital, Bahir Dar, Northwest Ethiopia: a retrospective cross-sectional study. Safety in Health. 2018;4(1):14.

8. Weldu MG, Berhane H, Berhe N, Haile K, Sibhatu Y, Gidey T, et al. Magnitude and Determinant Factors of Surgical Site Infection in Suhul Hospital Tigrai, Northern Ethiopia: A Cross-Sectional Study. Surgical infections. 2018;19(7):684-90.

9. Pittet D, Allegranzi B, Storr J, Nejad SB, Dziekan G, Leotsakos A, et al. Infection control as a major World Health Organization priority for developing countries. 2008;68(4):285-92.

10. de Lissovoy G, Fraeman K, Hutchins V, Murphy D, Song D, Vaughn BBJAjoic. Surgical site infection: incidence and impact on hospital utilization and treatment costs. 2009;37(5):387-97.

11. Cheadle WGJSi. Risk factors for surgical site infection. 2006;7(S1):s7-s11.

12. Bagnall NM VS, Trivedi P. . Surgical-site infection. Surgery research and practice. 2009;27:426-30.

13. Abdel-Aziz A, El-Menyar A, Al-Thani H, Zarour A, Parchani A, Asim M, et al. Adherence of surgeons to antimicrobial prophylaxis guidelines in a tertiary general hospital in a rapidly developing country. 2013;2013.

14. Hafez S ST, Hasan E, et al. . Incidence and modifiable risk factors of surveillance of surgical site infections in Egypt: A prospective study. Am J Infect Control. 2012;40:426-30.

15. De la Garza Ramos R NJ, Nasser R, et al. . Casecontrol study of risk factors for surgical site infection after three-column osteotomy for spine deformity. Turk Neurosurg. 2017;1.

16. Olsen MA NJ, Riew KD, et al. Risk factors for surgical site infection following orthopaedic spinal operations. J Bone Joint Surg. 2008; 90:62-9.

17. Mpogoro FJ MS, Mirambo MM, et al. . Incidence and predictors of surgical site infections following caesarean sections at Bugando Medical Centre, Mwanza, Tanzania. Antimicrob Resist Infect Control. 2014;2:25.

18. Laloto TL GD, Abdella SH. . Incidence and predictors of surgical site infection in Ethiopia: Prospective cohort. BMC Infect Dis 2017;17:119.

19. Waltz PK ZB. Surgical site infections and associated operative characteristics. Surg Infect. 2017;18:447-50.

20. Mawalla B, Mshana SE, Chalya PL, Imirzalioglu C, Mahalu WJBs. Predictors of surgical site infections among patients undergoing major surgery at Bugando Medical Centre in Northwestern Tanzania. 2011;11(1):21.

21. Safety WP. Forward programme, 2006-2007. Geneva: World Health Organization; 2006.

22. Ercole FF, Starling CEF, Chianca TCM, Carneiro MJBJoID. Applicability of the national nosocomial infections surveillance system risk index for the prediction of surgical site infections: a review. 2007;11(1):134-41.

23. Endalafer N, Gebre-Selassie S, Kotiso B. Nosocomial bacterial infections in a tertiary hospital in Ethiopia. Journal of Infection Prevention. 2011;12(1):38-43. 
24. Ducel G FJ, Nicolle L (eds). Prevention of Hospital-acquired Infections, 2nd ed. A Practical Guide. 2002;2002:12.

25. Amenu D, Belachew T, Araya F. Surgical site infection rate and risk factors among obstetric cases of Jimma University Specialized Hospital, Southwest Ethiopia. Ethiopian journal of health sciences. 2011;21(2):91-100.

26. Guta M, Aragaw K, Merid Y. Bacteria from infected surgical wounds and their antimicrobial resistance in Hawassa University Referral Teaching Hospital, Southern Ethiopia. African Journal of Microbiology Research. 2014;8(11):1118-24.

27. Lubega A, Joel B, Justina Lucy N. Incidence and etiology of surgical site infections among emergency postoperative patients in mbarara regional referral hospital, South Western Uganda. Surgery research and practice. 2017;2017.

28. Zafar Iqbal Malik TN, M Tariq Abdullah, S H Waqar, M A Zahid. Surgical Site Infections in General Surgical Wards at a Tertiary Care Hospital. Pak J Med Res. 2013;52.

29. Sohn AH, Parvez FM, Vu T, Hai HH, Bich NN, Le Thi AT, et al. Prevalence of surgical-site infections and patterns of antimicrobial use in a large tertiary-care hospital in Ho Chi Minh City, Vietnam. Infection Control \& Hospital Epidemiology. 2002;23(7):382-7.

30. Pathak A, Saliba EA, Sharma S, Mahadik VK, Shah H, Lundborg CS. Incidence and factors associated with surgical site infections in a teaching hospital in Ujjain, India. American journal of infection control. 2014;42(1):e11-e5.

31. Soleto L, Pirard M, Boelaert M, Peredo R, Vargas R, Gianella A, et al. Incidence of surgical-site infections and the validity of the National Nosocomial Infections Surveillance System risk index in a general surgical ward in Santa Cruz, Bolivia. Infection Control \& Hospital Epidemiology. 2003;24(1):26-30.

32. Miliani K, L'Hériteau F, Astagneau P, chemotherapy INSGJJoa. Non-compliance with recommendations for the practice of antibiotic prophylaxis and risk of surgical site infection: results of a multilevel analysis from the INCISO Surveillance Network. 2009;64(6):1307-15.

33. Pruzansky JS, Bronson MJ, Grelsamer RP, Strauss E, Moucha CS. Prevalence of modifiable surgical site infection risk factors in hip and knee joint arthroplasty patients at an urban academic hospital. The Journal of arthroplasty. 2014;29(2):272-6.

\section{Figures}




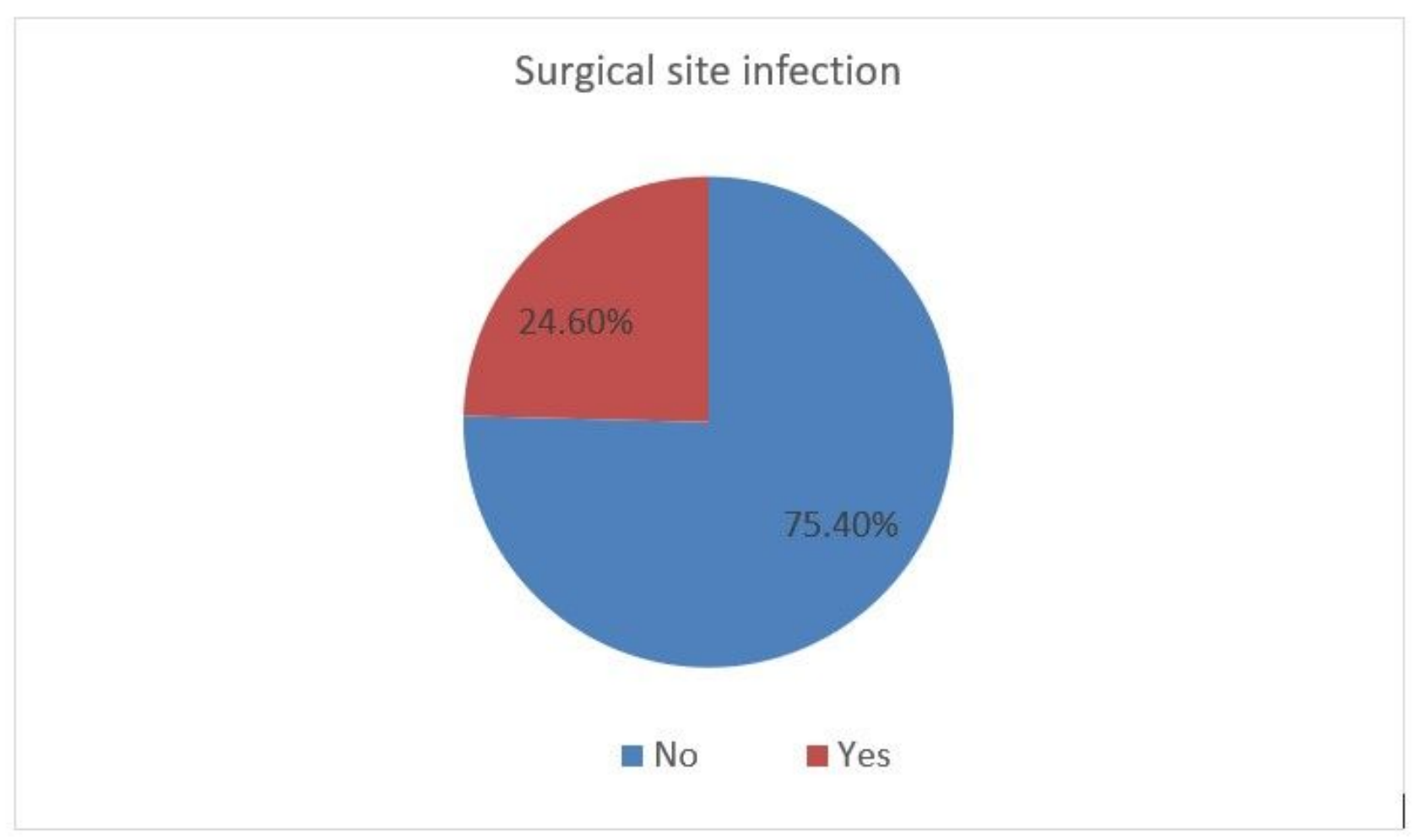

\section{Figure 1}

Prevalence of surgical site infection at Surgical ward of Hawassa University comprehensive specialized hospital, Hawassa, SNNPR, Ethiopia, from 1 March - 1 April 2019 ( $n=281)$. 